\title{
Column water vapor determination in night period with a lunar photometer prototype
}

\author{
A. Barreto ${ }^{1}$, E. Cuevas ${ }^{1}$, B. Damiri ${ }^{2}$, P. M. Romero ${ }^{1}$, and F. Almansa ${ }^{1}$ \\ ${ }^{1}$ Izaña Atmospheric Research Center, State Meteorological Agency of Spain (AEMET), Santa Cruz de Tenerife, Spain \\ ${ }^{2}$ Cimel Electronique, Paris, France \\ Correspondence to: E. Cuevas (ecuevasa@aemet.es)
}

Received: 1 December 2012 - Published in Atmos. Meas. Tech. Discuss.: 22 January 2013

Revised: 17 July 2013 - Accepted: 20 July 2013 - Published: 29 August 2013

\begin{abstract}
In this paper we present the preliminary results of atmospheric column-integrated precipitable water vapor (PWV) obtained with a new Lunar Cimel photometer (LC) at the high mountain Izaña Observatory in the period JulyAugust 2011. We have compared quasi-simultaneous nocturnal PWV from LC with PWV from a Global Positioning System (GPS) receiver and nighttime radiosondes (RS92). LC data have been calibrated using the Lunar Langley method (LLM). We complemented this comparative study using quasi-simultaneous daytime PWV from Cimel AERONET (CA), GPS and RS92. Comparison of daytime PWV from CA shows differences between GPS and RS92 up to $0.18 \mathrm{~cm}$. Two different filters, with and approximate bandwidth of $10 \mathrm{~nm}$ and central wavelengths at $938 \mathrm{~nm}$ (Filter\#1) and $937 \mathrm{~nm}$ (Filter\#2), were mounted onto the LC. Filter\#1 is currently used in operational AERONET sun photometers. PWV obtained with LC-Filter\#1 showed an overestimation above 0.18 and $0.25 \mathrm{~cm}$ compared to GPS and RS92, respectively, and root-mean-square errors (RMSEs) up to $0.27 \mathrm{~cm}$ and $0.24 \mathrm{~cm}$, respectively. Filter\#2, with a reduced out-of-band radiation, showed very low differences compared with the same references $(\leq 0.05 \mathrm{~cm})$ and RMSE values $\leq 0.08 \mathrm{~cm}$ in the case of GPS precise orbits.

These results demonstrate the ability of the new lunar photometer to obtain accurate and continuous PWV measurements at night, and the remarkable influence of the filter's transmissivity response to PWV determination at nighttime. The use of enhanced bandpass filters in lunar photometry, which is affected by more important inaccuracies than sun photometry, is necessary to infer PWV with similar precision to AERONET.
\end{abstract}

\section{Introduction}

Precipitable water vapor (PWV) is the total atmospheric water vapor contained in a vertical column of unit crosssectional area extending between any two specified levels. In this work we will refer to PWV as the column-integrated water vapor contained in a column of a unit cross section extended all the way up from the earth's surface to the top of the atmosphere.

Water vapor is the most important atmospheric greenhouse gas, and its phase changes involve exchanges of latent heat energy affecting the vertical stability of the atmosphere, the evolution of the weather and the energy balance of the global climate system (Chanine, 1992). There are indications that the amount of PWV is changing but at a very low rate, few tenths of mm per decade (Trenberth et al., 2005; Wagner et al., 2006), so high-quality worldwide long-term PWV monitoring is essential. PWV is currently observed by a number of sensors on board satellite platforms, such as the Moderate Resolution Imaging Spectroradiometer (MODIS) on Terra and Aqua platforms (Kaufman and Gao, 1992), the Atmospheric Infrared Sounder (AIRS) on board Aqua (Bedka et al., 2010) or the Infrared Atmospheric Sounding Interferometer (IASI) on board the EUMETSAT polar satellite MetOp (Pougatchev et al., 2009). Satellite-borne observations have the advantage of obtaining a global picture of PWV distribution on a daily basis, although with poor temporal resolution and point discrimination, and relatively high uncertainties associated with long-term monitoring due to the lack of sensor stability in time. These observations are complemented with ground-based remote sensing techniques, such as Global Positioning System (GPS) or sun photometry 
(e.g., Cimel/AErosol RObotic NETwork - AERONET - sun photometers), and thermodynamic radiosonde profiles (e.g., RS92). GPS uses the delay in radio signals due to the permanent dipole moment of water vapor molecules in the atmosphere to infer PWV (Duan et al., 1996), and the Vaisala RS92 radiosonde technique obtains direct measurement of water vapor as a function of height by means of a capacitance relative-humidity sensor (Miloshevich et al., 2009). Sun photometry measures atmospheric transmission of solar radiation within the $940 \mathrm{~nm}$ water vapor absorption band, and then obtains a column-averaged value of water abundance (Halthore et al., 1997). PWV can also be measured by means of other instruments, such as Raman lidar or microwave radiometers (Schmid et al., 2001; Brocard et al., 2013), as well as Fourier transform infrared spectrometry (FTIR) techniques (Buehler et al., 2012).

The ground-based remote sensing techniques are especially valuable for validating satellite PWV (Alexandrov et al., 2009) and for improving the temporal resolution and simplicity of PWV determination (Halthore et al., 1997). However, GPS delay technique shows poor precision $(\sim 20 \%)$ at low PWV conditions $(<3.5 \mathrm{~mm})$ (Schneider et al., 2010), so that this technique has significant limitations in dry regions, such as the subtropics and the poles. Raman lidar, FTIR technique and microwave radiometers are complex and expensive instruments to set up a global network. Radiosonde routine operation is also rather expensive, and for this reason they are flown normally only twice a day (around at 00:00 and 12:00 UTC) in a limited number of stations worldwide. PWV from radiosondes is basically obtained with integrated water vapor measured from ground to the upper troposphere. Miloshevich et al. (2009) estimated a precision of $\sim 5 \%$ in PWV derived using RS92 once an empirical correction procedure to remove the mean bias error in this instrument was implemented. In the upper troposphere and for very dry conditions, the precision of the PWV inferred using this technique is $\sim 10-20 \%$ (Schneider et al., 2010). Holben et al. (2001) estimated a precision in PWV from sun photometry of $\sim 10 \%$ as a result of the method for PWV retrieval and the relatively large uncertainty in the $V_{0}$ determined using the Langley method in $\sim 940 \mathrm{~nm}$ channel. Galkin et al. (2011) also estimated an uncertainty in photometry in $\sim 10 \%$, mainly affected by errors in instrument calibration.

Due to the high temporal resolution and simplicity of sun photometers, as well as the capacity of providing a quasicontinuous PWV information, this technique is widely used. Unfortunately, it is restricted to the light period. Thus, it becomes an important limitation for continuous PWV monitoring when strong variations are observed between day and night, in polar regions or in high mountain stations, in which background values, normally representative of free troposphere conditions during catabatic regime, are mostly present during the night. The unavailability of PWV data in periods of darkness is a real handicap to this technique.
In this study we have complemented the nocturnal aerosol optical depth study performed by Barreto et al. (2013) using a new lunar photometer prototype (Cimel Electronique CE-318U) with an analysis of PWV at night. Barreto et al. (2013) developed a new methodology to calibrate nocturnal photometers that can solve the problem of the moon's illumination variation during the course of the night - the Lunar Langley method (LLM).

This paper is organized as follows. The site of measurements is briefly described in Sect. 2. The main features of the new lunar photometer, as well as the ancillary information used for PWV validation, are shown in Sect. 3. In Sect. 4 we describe the methodology to obtain PWV with a lunar photometer. In Sect. 5 we analyze and compare quasisimultaneous nocturnal PWV obtained with a lunar photometer, using two different filters centered near $940 \mathrm{~nm}$, with coincident nocturnal data from GPS and RS92. In addition, we compare quasi-simultaneous daylight PWV obtained from AERONET, GPS and RS92. Finally, in Sect. 6 the discussion and the main conclusions are presented.

\section{Site information}

Izaña Observatory (IZO; www.aemet.izana.org) is a high mountain Global Atmospheric Watch (GAW) station located in Tenerife (the Canary Islands, Spain) at $28^{\circ} 18^{\prime} \mathrm{N}, 16^{\circ} 29^{\prime} \mathrm{W}$ and $2373 \mathrm{~m}$ a.s.l. It is part of the Izaña Atmospheric Research Center (IARC), managed by the State Meteorological Agency of Spain (AEMET). IZO is normally above the level of a strong and persistent subsidence temperature inversion that prevents pollution from the lower part of the island. The site is characterized by pristine skies, a high atmospheric stability, low and stable total column $\mathrm{O}_{3}$, and very low atmospheric humidity, resulting in a suitable site for background monitoring, representative of free troposphere conditions. These background conditions are reinforced during night period when a strong catabatic regime is well established. Thus, this site provides excellent conditions to perform an accurate calibration process using the Lunar Langley technique. In fact, Izaña Observatory is one of the two direct-sun calibration sites of the AERONET network. Radiation, in situ trace gases and aerosols, as well meteorological parameters, are continuously monitored within GAW. NDACC (Network for the Detection of Atmospheric Composition Change) FTIR, DOAS/UV-VIS, UV-Brewer and $\mathrm{O}_{3}^{-}$ ECC programs have been held for many years at IZO. RS92 soundings are launched twice a day (about at 23:15 and 11:15 UTC) from the Güímar station $\left(28^{\circ} 32^{\prime} \mathrm{N}, 16^{\circ} 38^{\prime} \mathrm{W}\right.$, $105 \mathrm{~m}$ a.s.l.), near the coast, approximately $15 \mathrm{~km}$ to the south of IZO. 


\section{Instrumentation}

\subsection{The new Lunar Cimel CE-318U}

The new Lunar Cimel CE-318U photometer (hereafter referred to as LC) is extensively described in Barreto et al. (2013). LC is in essence a quite similar instrument to the usual CE-318 sun photometer of AERONET (Holben et al., 1998), but with some significant technical modifications to optimize its performance for moon observations.

LC performs direct measurements at eight nominal wavelengths: $1640,1020,938,937,870,675,500$ and $440 \mathrm{~nm}$. The LC has been equipped with two band filters centered within water vapor absorption band, with an approximate full width at half maximum (FWHM) of $10 \mathrm{~nm}$, approximately centered at $940 \mathrm{~nm}$. This feature constitutes an interesting opportunity for investigating the PWV obtained with different interference filters. The two filters present the maximum transmissivity set at the central wavelength of 937 and $938 \mathrm{~nm}$, respectively.

Filter\#1, centered at $938 \mathrm{~nm}$, is the current band filter used by the AERONET CE-318 sun photometers. It presents a transmissivity up to 0.7 and an important contribution of wavelengths outside the FWHM (Fig. 1). Out-of-band values are called "wings of the filter". However, Filter\#2 is characterized by flat shape transmissivity close to 1 at central wavelength of $937 \mathrm{~nm}$ with negligible out-of-band radiation effect.

In the present study we have compared PWV obtained with these two LC filters with markedly different transmission responses. To do this, we have performed direct moon measurements in the periods from 11 to 15 July 2011 and from 9 to 16 August 2011. In the first period, the moon's fraction of illumination ranges from $87 \%$ (11 July) to full moon (15 July). In the second one, it ranges from $84 \%$ (9 August) to full moon (13 August).

\subsection{Ancillary information for PWV validation}

AERONET Version 2 Level 1.5 data were obtained using the Izaña AERONET Master Cimel \#244 (http://aeronet.gsfc. nasa.gov), hereafter referred to as $\mathrm{AC}$, for days before and after each nocturnal LC observation. This information is automatically cloud-screened using the methodology proposed by Smirnov et al. (2000) and quality-assured following the AERONET protocol (Holben et al., 1998). PWV was measured from direct sun measurements in the $\sim 940 \mathrm{~nm}$ channel. Following Holben et al. (2001), due to the uncertainties involved in extracting PWV from the water vapor transmittance $\left(T_{\mathrm{w}, \lambda}\right)$ and the relatively large uncertainty (between $2-$ $4 \%$ ) in the modified Langley $V_{0}$ as a result of water vapor variability, an estimated uncertainty of $\pm 10 \%$ is expected for PWV derived from sun photometry.

The radio signals of GPS and GLONASS (the Russian GPS) are delayed due to refraction in the atmosphere, mainly caused by water vapor. The zenith total delay (ZTD) is

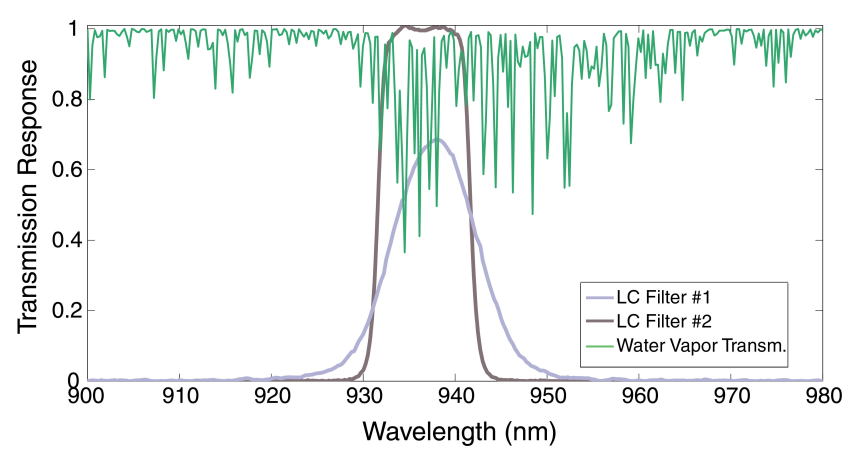

Fig. 1. Filter transmission responses associated with both LC channels located within water vapor absorption band. MODTRAN midlatitude summer water vapor transmission is also included.

the sum of the zenith hydrostatic delay (ZHD), associated with induced dipole moments of the atmospheric molecules (the dry component), and the zenith wet delay (ZWD) related to the permanent dipole moments of the water vapor molecules (Duan et al., 1996). A Leica GRX 1200GG pro GPS/GLONASS receiver has been operated at IZO within the European Reference Frame network (EUREF, Bruyninx, 2004) since July 2008. This instrument belongs to the Spanish National Geographic Institute (IGN), and provides instantaneous ZTD values every 15 min (GPS ultra-rapid orbits) by applying the Bernese software (Rothacher, 1992, 1993), as well as $1 \mathrm{~h}$ resolution instantaneous ZTD values postprocessed with higher accuracy (GPS precise orbits). The last product is based on a differential positioning approach that requires the combination of GPS data from at least two receivers, in addition to other orbital parameters (Kouba, 2009). The ZHD is calculated at IZO with the actual surface pressure at the station, which is measured with a highprecision SETRA 470 barometer. The ZHD is typically one order of magnitude larger than the ZWD. The ZWD is then converted to PWV using the refraction constants of water vapor ("map function") derived from column-averaged temperature obtained from radiosondes. This method is described by Romero et al. (2009). The Izaña's GPS/GLONASS receiver is part of the EUMETNET (the Network of European Meteorological Services) GPS water vapor program (EGVAP). According to Schneider et al. (2010), the GPS technique has a detection limit in column water vapor of $3.5 \mathrm{~mm}$, and below this threshold the GPS systematically underestimates the PWV. Above $3.5 \mathrm{~mm}$, the GPS accuracy is better than $10 \%$, an estimated error of $0.7 \mathrm{~mm}$, and a small bias with respect to FTIR data is observed (Schneider et al., 2010).

Vaisala RS92 radiosonde water vapor measurements have been included in this comparison. Meteorological radiosondes have been launched twice a day $(\sim 23: 15$ and $\sim$ 11:15 UTC) from a radiosonde station (Güímar, Tenerife) situated at the coastline, approximately $15 \mathrm{~km}$ to the south 
of Izaña. Güímar radiosonde World Meteorological Organization (WMO) station \#60018 is part of Global Climate Observing System (GCOS)-Upper-Air Network (GUAN). The RS92 sonde performs relative humidity measurements as a function of height using a thin-film capacitance that is proportional to the ambient water vapor concentration (Miloshevich et al., 2009). Data have been corrected by temperature and radiation dependence (in the case of daytime soundings) following Romero et al. (2011). The estimated precision is $5 \%$ for total column water vapor in the lower and middle troposphere, although the precision is significantly lower (about 10-20\%) in the upper troposphere and for very dry conditions (Miloshevich et al., 2009; Schneider et al., 2010). Schneider et al. (2010) estimated a RS92's PWV precision of $15 \%$ by comparison with FTIR, this being precision independent of atmospheric conditions.

\section{Methodology}

The Beer-Lambert-Bouguer law can be applied over small band passes characterized by reduced spectral variation in atmospheric transmittance (Schmid et al., 1996). In those regions affected by strong spectral variation of molecular absorption, as occurred in near-infrared water vapor absorption band, this law must be modified taking into account the water vapor transmittance $\left(T_{\mathrm{w}, \lambda}\right)$,

$V(\lambda)=V_{0, \lambda} \cdot \exp \left(-m(\theta) \cdot \tau_{\lambda}\right) \cdot T_{\mathrm{w}, \lambda}$.

$V_{\lambda}$ is the output voltage, $V_{0, \lambda}$ the extraterrestrial voltage, $m$ the atmospheric air mass, $\theta$ the moon's zenith angle and $\tau_{\lambda}$ the spectral optical depth. Neglecting the absorption due to $\mathrm{O}_{3}$ and $\mathrm{NO}_{2}$ in this spectral range, only the contribution of water vapor, Rayleigh and aerosols are considered in Eq. (1), and thus

$V_{\lambda}=V_{0, \lambda} \cdot \exp \left(-m_{\mathrm{R}}(\theta) \cdot \tau_{\mathrm{R}, \lambda}-m_{\mathrm{a}}(\theta) \cdot \tau_{\mathrm{a}, \lambda}\right) \cdot T_{\mathrm{w}, \lambda}$.

$\tau_{\mathrm{R}}$ and $\tau_{\mathrm{a}}$ represent the Rayleigh and aerosol optical depths, respectively. Meanwhile, $m_{\mathrm{R}}$ and $m_{\mathrm{a}}$ are the Rayleigh and aerosol air masses. $T_{\mathrm{w}, \lambda}$ can be defined as the band-weighted water vapor transmittance (Thomason, 1985),

$T_{\mathrm{w}, \lambda}=\frac{\int_{\lambda_{1}}^{\lambda_{2}} E_{0}(\lambda) \cdot S(\lambda) \cdot \exp \left(-m_{\mathrm{w}} \cdot \tau_{\mathrm{w}}(\lambda)\right) \mathrm{d} \lambda}{\int_{\lambda 1}^{\lambda_{2}} E_{0}(\lambda) \cdot S(\lambda) \mathrm{d} \lambda}$,

where $\tau_{\mathrm{w}, \lambda}$ is the strongly varying water vapor absorption optical depth, $E_{0}(\lambda)$ the exo-atmospheric solar irradiance and $S(\lambda)$ the instrument response in each channel. The parameter $m_{\mathrm{w}}$ represents the water vapor optical air mass. The dependence of $T_{\mathrm{w}, \lambda}$ on the PWV was studied by Bruegge et al. (1992), showing the following exponential dependence,

$T_{\mathrm{W}, \lambda}=\exp \left(-a \cdot\left(m_{\mathrm{w}}(\theta) \cdot \mathrm{PWV}\right)^{b}\right)$.

In this equation, " $a$ " and " $b$ " constants can be determined by fitting the weighted water vapor transmittances simulated
Table 1. Coefficients $a$ and $b$ obtained for Filter\#1 centered at $938 \mathrm{~nm}$ and Filter\#2 at $937 \mathrm{~nm}$.

\begin{tabular}{ccc}
\hline & Filter\#1 & Filter\#2 \\
\hline$a$ & 0.5145 & 0.5929 \\
$b$ & 0.5607 & 0.5777 \\
\hline
\end{tabular}

by a radiative transfer model for an instrument-specific filter function. Thus, a fitting plot of $\ln \left(\ln \left(\frac{1}{T_{\mathrm{w}}}\right)\right)$ against $\ln \left(m_{\mathrm{w}}\right.$. PWV) results in a line with a slope equal to " $b$ ", and an intercept of $\ln (a)$. As Halthore et al. (1997) showed, these constants depend on wavelength position, the width and shape of the photometer filter functions, the atmospheric pressure and temperature as well as the vertical distribution of water vapor. They also pointed out that water abundance is not sensitive to the position of the filter within the absorption band. These authors estimated the error in PWV due to this effect to values typically $<1 \%$, pointing to the filter bandwidth as the principal source of error, apart from the instrument calibration errors. However, the importance of using different narrowband filter responses was not clearly established in this study. Ortiz de Galisteo et al. (2009) showed the importance of the "wings of the filter" effect, which might introduce an overestimation in the aerosol optical depth, and thus inaccuracies in PWV retrieval due to uncertainties in Rayleigh and gaseous absorption total optical depth. This problem was also studied by Alexandrov et al. (2009). These authors suggested blocking background transmittances from $10^{-4}$ to $10^{-7}$. Furthermore, they showed that a background transmittance $\sim 10^{-4}$ led to an error in aerosol optical depth up to $10 \%$ and significant variations in " $a$ " and " $b$ " parameters in the $T_{\mathrm{w}}-\mathrm{PWV}$ exponential dependence found by Bruegge et al. (1992). Finally, Galkin et al. (2011) showed that " $a$ " parameter depends on the half-width and shape of the filter transmission curve, pressure, temperature and water vapor content, while " $b$ " appears only to depend on the latter effect.

In this study we have used the radiative code MODTRAN 4.0 to estimate water vapor transmittances. In order to account for nocturnal humidity conditions, 153 vertical soundings launched at $\sim 23: 15$ UTC from the AEMET Guiímar station have been introduced in the radiative code. A variation of $\theta$ between 0 and $80^{\circ}$ in each profile has been considered to introduce PWV variation. Following the exponential dependence of $T_{\mathrm{W}}$ with respect to PWV presented in Eq. (4), we have calculated the filter-dependent constants (" $a$ " and " $b$ "). Values of " $a$ " and " $b$ " for the two LC water vapor bands are given in Table 1.

Combining Eqs. (2) and (4), PWV can be determined using the following equation:

$\mathrm{PWV}=\frac{1}{m_{\mathrm{W}}} \cdot\left\{\frac{1}{a} \cdot\left[\ln \left(\frac{V_{0, \lambda}}{V_{\lambda}}\right)-m_{\mathrm{R}} \cdot \tau_{\mathrm{R}_{\lambda}}-m_{\mathrm{a}} \cdot \tau_{\mathrm{a}, \lambda}\right]\right\}^{\frac{1}{b}}$.

$V_{0}$ is obtained in sun photometry by means of the Langley plot method once $\tau_{\mathrm{a}}$ within the $\sim 940 \mathrm{~nm}$ water vapor 
absorption band is estimated following the AERONET version 2 protocol by extrapolation of $\tau_{\mathrm{a}, \lambda}$ at 870 and $440 \mathrm{~nm}$. In the case of lunar photometry, Barreto et al. (2013) developed the LLM as a calibration method to account for the moon's illumination variations inherent to the lunar cycle. This new methodology is suitable to calibrate nocturnal photometers under changeful illumination conditions. These authors found similar nocturnal $\tau_{\mathrm{a}}$ uncertainties using this method to those associated with the usual solar langleys (i.e., \pm 0.02 for 500 and $440 \mathrm{~nm}$ channels, and \pm 0.01 for longer wavelengths channels). This method considers the extraterrestrial voltage as

$V_{0, \lambda}=I_{0, \lambda} \cdot \kappa_{\lambda}$.

The spectral calibration coefficients $\left(\kappa_{\lambda}\right)$ in this equation depend on the instrument's features (Barreto et al., 2013). $I_{0, \lambda}$ is the extraterrestrial irradiance estimated from the lunar irradiance model presented in Kieffer and Stone (2005). This empirical model, known as ROLO (RObotic Lunar Observatory), estimates the exoatmospheric lunar irradiance using a telescope system with the capability to perform measurement at 32 different VNIR (visible and near-infrared) and SWIR (short-wave infrared) passbands. However, a continuum lunar irradiance spectrum was obtained from a smoothing analysis of the discrete ROLO irradiances, and therefore $I_{0, \lambda}$ values for each LC bands were obtained by convolving spectral irradiances with filter response functions. The orbital parameters required as ROLO inputs were computed using the astronomical calculator Alcyone 4.0.

Following Barreto et al. (2013), the instrument calibration was performed using lunar data obtained on 8-9 February 2012. This night was selected due to the relatively low and constant aerosol concentration, especially during the moonset, when the aerosol optical depth at $440 \mathrm{~nm}$ remained stable and near 0.02 . The $\kappa_{\lambda}$ 's for each channel are presented in Table 2.

Once the calibration coefficients have been calculated, $\tau_{\mathrm{a}}$ values for Filter\#1 and Filter\#2 are retrieved by extrapolation of 870 and $440 \mathrm{~nm}$ values. Then, both calibration coefficients in the water vapor absorption band ( $\kappa_{\mathrm{wv}}$ 's) are calculated using a fitting plot, and PWV can be obtained as follows:

$\mathrm{PWV}=\frac{1}{m_{\mathrm{w}}} \cdot\left\{\frac{1}{a} \cdot\left[\ln \left(\frac{I_{0, \mathrm{wv}}}{V_{\mathrm{wv}}}\right)+\ln \left(\kappa_{w v}\right)-m_{\mathrm{R}} \cdot \tau_{\mathrm{R}, \mathrm{wv}}-m_{\mathrm{a}} \cdot \tau_{\mathrm{a}, \mathrm{wv}}\right]\right\}^{\frac{1}{b}}$

Due to the high spatial and temporal variability of the atmospheric water vapor, it is particularly important to establish an adequate coincidence criterion for comparing PWV measurements from different techniques. Since GPS from ultrarapid orbits (GPS-U) provides PWV data every $15 \mathrm{~min}$, we have considered quasi-simultaneous GPS-U/LC and GPSU/CA measurements when they overlap within \pm 6 min. In the case of GPS hourly data from precise orbits (GPS-P), we have considered a time interval of $\pm 20 \mathrm{~min}$. Regarding comparisons against RS92 PWV data, as we have only two

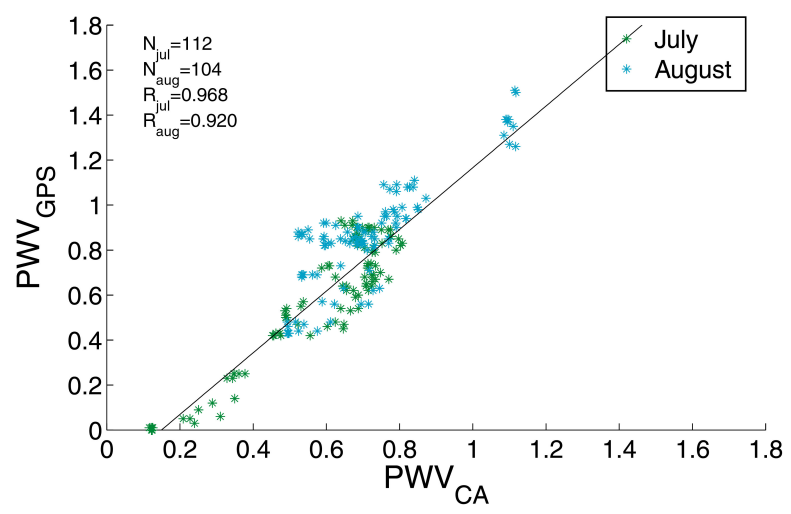

Fig. 2. Correlation between PWV (cm) obtained by means of GPS$\mathrm{U}$ and CA database. The number of pairs and the correlation coefficient $(R)$ for each month have been included. The solid line represents the linear regression line.

values per day $(\sim 23: 15$ and $\sim 11: 15$ UTC $)$, we have compared LC-RS92 PWV within the 22:00-0:00 UTC time period, and RS92/CA PWV within 10:00-12:00 UTC.

\section{Results}

Filter-dependent constants were determined using Eq. (4) and MODTRAN 4.0 radiative code, assuming specific nocturnal and local conditions (Table 1). We can see from Table 1 that " $b$ " coefficients are similar for both filters, while " $a$ " coefficients are appreciably different. As " $a$ " represents the intercept of the $T_{\mathrm{w}}-\mathrm{PWV}$ fitting line, this result points out the impact of the filter function shape on the PWV retrieval. These results are consistent with those presented in Galkin et al. (2011), where a dependence of the " $a$ " parameter on the half-width and shape of the filter function was found. Meanwhile, the parameter " $b$ " can be considered less affected by the transmission curve. In our case, the lower " $a$ " coefficient found for Filter\#1 is due to the overestimation of $T_{\mathrm{w}}$ as a result of the out-of-band radiation effect. The correlation coefficient $R$ of the fitting plot is 0.99 for the two filters.

The comparison of GPS-U/AC pairs and GPS-U/LC pairs for both filters centered at $937 \mathrm{~nm}$ and $938 \mathrm{~nm}$ using the LLM for 11-15 July and 9-16 August is presented in Figs. 2 and 3 , respectively. The comparison during daytime has been performed with 112 pairs for July and 104 for August, respectively. The correlation coefficients $(R)$ are 0.97 for July and 0.92 for August. GPS-U and LC data have been compared using 81 pairs in July and 103 in August. Correlation coefficients are 0.90 and 0.98 in July and August for Filter\#1 and Filter\#2, respectively. These values are slightly lower than those obtained during July daytime, and slightly higher than $R$ values for August daytime. Linear regressions displayed in Figs. 2 and 3 verify the strong linear relationship between these variables. 
Table 2. $\kappa_{j}$ calibration coefficients $\left(\mathrm{W}^{-1} \mathrm{~m}^{2} \mathrm{nmDC}\right)$ extracted for each LC channel obtained during the moonset of 9 February 2012.

\begin{tabular}{ccccccccc}
\hline Channel & 1020 & 1640 & 938 & 937 & 870 & 675 & 500 & 440 \\
\hline$\kappa_{j}$ & $2.15 \times 10^{9}$ & $1.28 \times 10^{10}$ & $3.36 \times 10^{9}$ & $3.37 \times 10^{9}$ & $3.02 \times 10^{9}$ & $2.29 \times 10^{9}$ & $1.74 \times 10^{9}$ & $1.41 \times 10^{9}$ \\
\hline
\end{tabular}
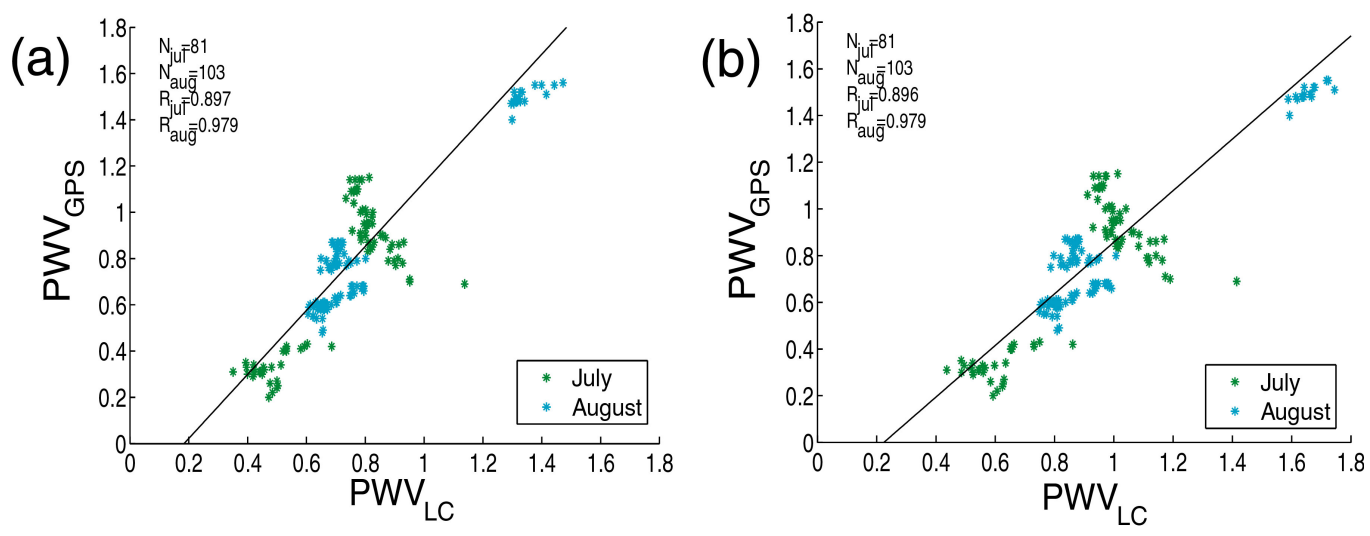

Fig. 3. PWV-GPS (cm) from ultra-rapid orbits versus PWV-LC (cm) for channels centered at (a) $937 \mathrm{~nm}$ (Filter\#2) and (b) $938 \mathrm{~nm}$ (Filter\#1). The number of pairs and the correlation coefficient $(R)$ for each month have been included. The solid line represents the linear regression line.

PWV differences between sun/moon photometers versus GPS-U, GPS-P and RS92 are quantified in Tables 3, 4 and 5 , where the mean value, the standard deviation $(\sigma)$ and the root-mean-square error (RMSE) are presented. We can notice from Table 3 that higher dispersions between LC and GPS-U PWV values are found in July $(0.18 \mathrm{~cm}$ and $0.14 \mathrm{~cm}$ for Filter\#1 and Filter\#2, respectively). This behavior is also shown in Fig. 3a for GPS-U data $>0.7 \mathrm{~cm}$ and in Fig. $3 \mathrm{~b}$ for values $>0.6 \mathrm{~cm}$. A detailed analysis developed for July nighttime data found this unexpected behavior is the consequence of uncertainties in PWV extracted from GPS-U on 14 July. In fact, important discrepancies between ZWD signal retrieved using ultra-rapid and precise orbits were observed during this night. The GPS-P/LC comparison is presented in Table 4. It shows how $\sigma$ and RMSE are notably reduced in the case of LC-Filter\#2 comparison during July.

In Figs. 4 and 5 the daily PWV evolution for LC, CA, GPS-U and RS92 in July and August cases, respectively, are displayed jointly with the vertical water vapor partial pressure cross sections from the radiosonde (upper panel). In these figures daytime information corresponds to PWV extracted approximately at 11:15 UTC and nighttime to data $\sim 23: 15$ UTC. From Table 3 we obtained a significant low bias $(<0.02 \mathrm{~cm})$ in the comparison between LC-Filter\#2 and GPS-U for July, similar to those found for GPS-U/CA $(-0.01 \mathrm{~cm})$, but RMSE values up to $0.19 \mathrm{~cm}$. Table 5 shows that the best scores for RS92 and sun/moon photometer comparison in July were obtained for RS92/LC-Filter\#2 $(0.03 \mathrm{~cm})$, with the lowest differences, standard deviation and RMSE. These values are within the estimated PWV precision
Table 3. Mean, standard deviation $\sigma$ and RMSE $(\mathrm{cm})$ of the PWV difference (photometer minus GPS data) obtained from the comparison study between diurnal CA, nocturnal LC and GPS (ultra-rapid orbits).

\begin{tabular}{lcrr}
\hline & & \multicolumn{2}{c}{ GPS (ultra-rapid) } \\
& & July & August \\
\hline AERONET Cimel & Mean and $\sigma$ & $-0.01 \pm 0.13$ & $-0.16 \pm 0.11$ \\
& RMSE & 0.13 & 0.18 \\
& & & \\
Lunar Cimel (Filter\#1) & Mean and $\sigma$ & $0.18 \pm 0.18$ & $0.19 \pm 0.10$ \\
& RMSE & 0.25 & 0.24 \\
Lunar Cimel (Filter\#2) & Mean and $\sigma$ & $-0.01 \pm 0.14$ & $-0.01 \pm 0.11$ \\
& RMSE & 0.19 & 0.11 \\
\hline
\end{tabular}

Table 4. Mean, standard deviation $\sigma$ and RMSE (cm) of the PWV difference (photometer minus GPS data) obtained from the comparison study between diurnal CA, nocturnal LC and GPS (precise orbits).

\begin{tabular}{lcrr}
\hline & & \multicolumn{2}{c}{ GPS (precise) } \\
& & July & August \\
\hline AERONET Cimel & Mean and $\sigma$ & $-0.11 \pm 0.12$ & $-0.14 \pm 0.09$ \\
& RMSE & 0.16 & 0.17 \\
Lunar Cimel (Filter\#1) & Mean and $\sigma$ & $0.24 \pm 0.11$ & $0.25 \pm 0.08$ \\
& RMSE & 0.27 & 0.25 \\
Lunar Cimel (Filter\#2) & Mean and $\sigma$ & $0.05 \pm 0.05$ & $0.03 \pm 0.07$ \\
& RMSE & 0.07 & 0.08 \\
\hline
\end{tabular}




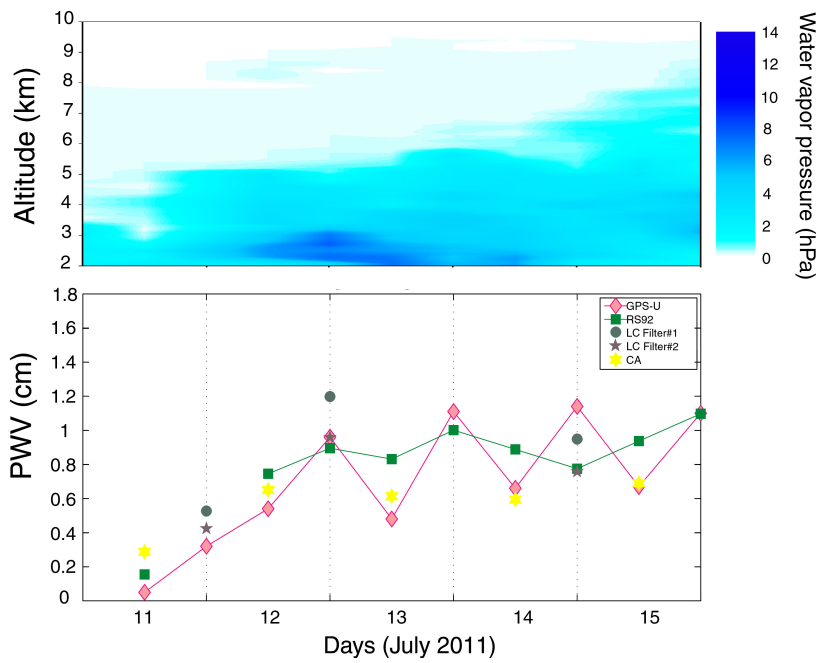

Fig. 4. Daily evolution of PWV (cm) obtained in July at daytime $(\sim 11: 15$ UTC) and nighttime ( 23:15 UTC) using CA and LC, as well as GPS-U and RS92. In the upper panel is presented the vertical daily evolution of water vapor pressure $(\mathrm{hPa})$ during this period obtained from radiosonde data.

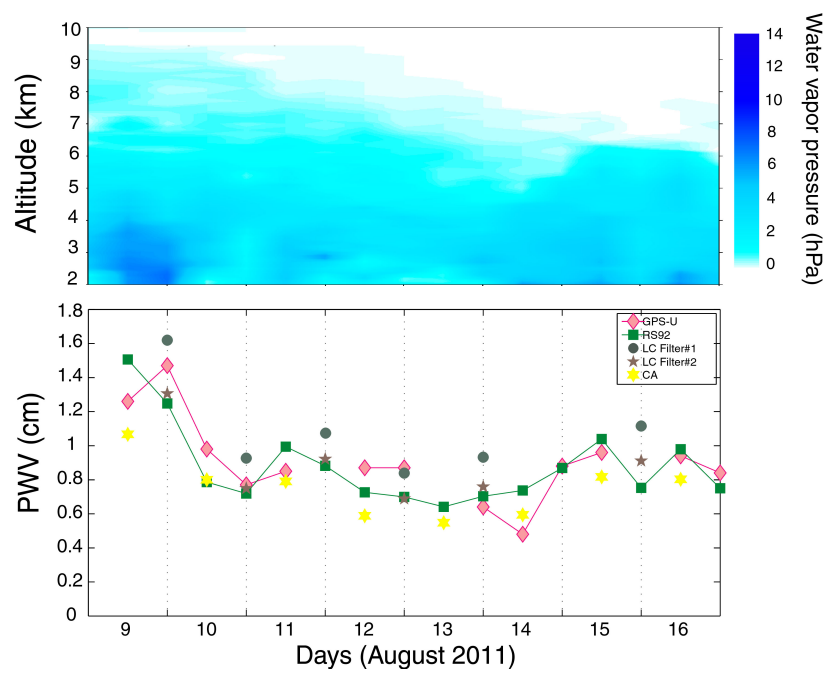

Fig. 5. Daily evolution of PWV $(\mathrm{cm})$ obtained in August at daytime ( 11:15 UTC) and nighttime ( 23:15 UTC) using CA and LC, as well as GPS-U and RS92. In the upper panel is presented the vertical daily evolution of water vapor pressure $(\mathrm{hPa})$ during this period obtained from radiosonde data.

for both techniques (Holben et al., 2001; Schneider et al., 2010). However, higher discrepancies were obtained when comparing GPS-U and LC-Filter\#1 $(\sim 0.18 \mathrm{~cm})$, RS92 and CA $(-0.14 \mathrm{~cm})$ and RS92 and LC-Filter\#1 $(0.26 \mathrm{~cm})$. RMSE values for these comparisons were also higher, up to $0.25 \mathrm{~cm}$. Figure 4 shows there is a good agreement between GPSU/LC-Filter\#2, GPS-U/CA as well as RS92/LC-Filter\#2, in spite of the relatively high PWV difference GPS-U/CA found for 11 July. It is probably due to the fact that PWV was below $0.35 \mathrm{~cm}$, the threshold defined as GPS detection limit by
Table 5. Mean, standard deviation $\sigma$ and RMSE $(\mathrm{cm})$ of the PWV difference (photometer minus RS92 data) obtained from the comparison study between diurnal CA, nocturnal LC and RS92 data.

\begin{tabular}{cccc}
\hline & & \multicolumn{2}{c}{ RS92 } \\
& & July & August \\
\hline AERONET Cimel & Mean and $\sigma$ & $-0.14 \pm 0.15$ & $-0.18 \pm 0.12$ \\
& RMSE & 0.21 & 0.21 \\
Lunar Cimel (Filter\#1) & Mean and $\sigma$ & $0.26 \pm 0.04$ & $0.25 \pm 0.07$ \\
& RMSE & 0.19 & 0.24 \\
Lunar Cimel (Filter\#2) & Mean and $\sigma$ & $0.03 \pm 0.02$ & $0.02 \pm 0.10$ \\
& RMSE & 0.03 & 0.10 \\
\hline
\end{tabular}

Schneider et al. (2010). This dry period was well depicted by the vertical water vapor partial pressure cross section of the radiosonde. It was followed by a notable increase of atmospheric humidity in levels lower than $3 \mathrm{~km}$ height, especially during 12 and 13 July. During 12 July at nighttime, relatively high PWV values $(\sim 1 \mathrm{~cm})$ were recorded by LC-Filter\#2, GPS-U and RS92. PWV from LC-Filter\#1 reached $1.2 \mathrm{~cm}$. Daytime RS92 data on 13 July presented similar PWV values to the previous night, while PWV values extracted by GPS$\mathrm{U}$ and CA were considerably lower $(<0.6 \mathrm{~cm})$. According to radiosonde data, the atmospheric humidity remained high and nearly constant from 12 to 13 July, decreasing and being restricted to lower levels from 14 July. This reduction was more pronounced from the last part of 14 July on. It was well captured by LC-Filter\#2, while GPS-U reported values $>1.1 \mathrm{~cm}$. This high PWV value is expected considering the high dispersion found previously in Table 3 and Fig. 3. As we mentioned before, it is the consequence of uncertainties in PWV extracted from GPS-U during this night.

In relation to August data, similar PWV differences were shown in Tables 3 and 5 for RS92/CA $(-0.18 \mathrm{~cm})$, GPSU/LC-Filter\#2 $(0.01 \mathrm{~cm})$ and GPS-U/LC-Filter\#1 $(0.19 \mathrm{~cm})$. Meanwhile, more pronounced discrepancies were obtained in the GPS-U/CA and RS92/CA comparisons. In Table 4 similar $\sigma$ and RMSE to Table 3 were found, although higher bias in the GPS-P versus LC-Filter\#1 was obtained. Figure 5 shows a lower temporal variability in PWV during August than it was displayed in July, when only a few increases in PWV occurred. This PWV evolution is well tracked by GPS$\mathrm{U}$ and LC-Filter\#2. PWV decreased from daytime to nighttime period on 9 August, and it continued decreasing until 10 August at night, when a good agreement between GPS-U, RS92 and LC-Filter\#2 was found. GPS-U and CA PWV values on 11 August were quite similar. Meanwhile, RS92 detected PWV values near $1 \mathrm{~cm}$. Nighttime data present again a good concordance between RS92 and LC-Filter\#2. Lower and more stable PWV values were expected for the next twoday period, as those displayed by CA, LC-Filter\#2 and RS92. After this period, the atmospheric humidity experimented a notable increase, reaching values $>1 \mathrm{~cm}$ on 15 August. Lower values were retrieved by CA. 


\section{Summary and conclusions}

The preliminary results of nocturnal PWV performed in this study demonstrate that LC-Filter\#1 and Filter\#2 correlate quite well to PWV from GPS. These regressions were similar to those obtained by means of diurnal CA data. LCFilter\#2 and GPS absolute PWV differences in July and August were very low $(0.01 \mathrm{~cm}$ for GPS-U and up to $0.05 \mathrm{~cm}$ for GPS-P), as well as between AC and GPS-U differences in July at daytime $(0.01 \mathrm{~cm})$. GPS-P/LC-Filter\#2 comparison shows the lower RMSE values, up to $0.08 \mathrm{~cm}$. Oppositely, CA underestimated notably PWV from GPS in August cases (up to $0.16 \mathrm{~cm}$ and $0.14 \mathrm{~cm}$ for ultra-rapid and precise orbits, respectively), and an overestimation of GPS $\sim 0.25 \mathrm{~cm}$ was found for LC-Filter\#1 at nighttime. The comparative study between Cimel daytime and nighttime PWV with RS92 information showed again a good concordance in the case of LC-Filter\#2, with differences $\leq 0.03 \mathrm{~cm}$, and RMSE $<0.10 \mathrm{~cm}$. However, LC-Filter\#1 RMSE and absolute differences were notably higher, up to $0.26 \mathrm{~cm}$, as well as diurnal differences and RMSE (up to $0.21 \mathrm{~cm}$ ), above the instrument's expected precision. These quantitative results were confirmed by a qualitatively study of the daily PWV evolution within the period of study. We have found that LCFilter\#2 and RS92 present a pretty good agreement, providing notably similar values during the whole period. Reasonable PWV daily differences in relation to GPS data were also obtained, being within the expected accuracy for these instruments (Schneider et al., 2010).

Finally, it is important to highlight the systematic differences in PWV obtained for both LC filters. Since the central wavelengths of these channels differ in approximately $1 \mathrm{~nm}$ and they have a similar FWHM, it proves that water vapor data inferred by filter radiometry are very sensitive to the filter's shape. Although the filter transmission inside the LCFilter\#1 wings is very low, the relatively strong transmission of water vapor in this spectral range supposes a significant contribution that must be taken into account. The radiation transmitted by Filter\#1 outside the FWHM, or out-of-band radiation, led us to " $a$ " and " $b$ " values lower than expected and therefore errors in the spectral calibration coefficients $\left(\kappa_{\mathrm{wV}}\right)$ in this spectral range. On the contrary, the contribution of out-of-band radiation in Filter\#2 can be negligible, and thus a more accurate PWV determination can be carried out using this filter, as our results showed. Thus, we have confirmed that in case we have information from a filter with a relatively high contribution in the wings, it is necessary to block the out-of-band radiation.

To conclude, this paper proves the ability of the new CE318U Lunar Cimel to perform accurate nocturnal column water vapor measurements, comparable to the accuracy of other similar techniques. It could be of considerable importance to fill the gaps in PWV inferred using sun photometry as well as to provide a continuous sequence of PWV measurements at night. In addition, the use of improved interference filters with higher transmission responses is proven to reduce considerably inaccuracies in PWV determination at nighttime. Since lunar photometry is affected by more important inaccuracies than sun photometry, the use of enhanced bandpass filters is essential to obtain accurate PWV with a precision similar to that of the AC.

Acknowledgements. The authors wish to thank Cimel for providing the prototype used in this work as well as all the technical support to conclude this study. In addition, we would like thank to the security staff at Izaña Observatory for kindly supporting the nocturnal operation of the lunar photometers. Finally, the AERONET sun photometer at Izaña has been calibrated within AERONETEUROPE TNA supported by the European Community - Research Infrastructure Action under the FP7 "Capacities" specific program for Integrating Activities, ACTRIS grant agreement no. 262254.

Edited by: O. Dubovik

\section{References}

Alexandrov, M. D., Schmid, B., Turner, D. D., Cairns, B., Oinas, V., Lacis, A. A., Gutman, S. I., Westwater, E. R., Smirnov, A., and Eilers, J.: Columnar water vapor retrievals from multifilter rotating shadowband radiometer data, J. Geophys. Res., 114, D02306, doi:10.1029/2008JD010543, 2009.

Barreto, A., Cuevas, E., Damiri, B., Guirado, C., Berkoff, T., Berjón, A. J., Hernández, Y., Almansa, F., and Gil, M.: A new method for nocturnal aerosol measurements with a lunar photometer prototype, Atmos. Meas. Tech., 6, 585-598, doi:10.5194/amt-6-585-2013, 2013.

Bedka, S., Knuteson, R., Revercomb, H., Tobin, D., and Turner, D.: An assessment of the absolute accuracy of the Atmospheric Infrared Sounder v5 precipitable water vapor product at tropical, midlatitude, and arctic ground-truth sites: September 2002 through August 2008, J. Geophys. Res., 115, D17310, doi:10.1029/2009JD013139, 2010.

Brocard, E., Philipona, R., Haefele, A., Romanens, G., Mueller, A., Ruffieux, D., Simeonov, V., and Calpini, B.: Raman Lidar for Meteorological Observations, RALMO - Part 2: Validation of water vapor measurements, Atmos. Meas. Tech., 6, 1347-1358, doi:10.5194/amt-6-1347-2013, 2013.

Bruegge, C. J., Conel, J. E., Green, R. O., Margolis, J. S., Holm, R. G., and Toon, G.: Water vapor column abundances retrievals during FIFE, J. Geophys. Res., 97, 18759-18768, 1992.

Buehler, S. A., Östman, S., Melsheimer, C., Holl, G., Eliasson, S., John, V. O., Blumenstock, T., Hase, F., Elgered, G., Raffalski, U., Nasuno, T., Satoh, M., Milz, M., and Mendrok, J.: A multiinstrument comparison of integrated water vapour measurements at a high latitude site, Atmos. Chem. Phys., 12, 10925-10943, doi:10.5194/acp-12-10925-2012, 2012.

Chahine, M. T.: The hydrological cycle and its influence on climate, Nature, 359, 373-380, 1992.

Duan, J., Bevis, M., Fang, P., Bock, Y., Chiswell, S., Businger, S., Rocken, C., Solheim, F., van Hove, T., Ware, R., McClusky, S., Herring, T. A., and King, R. W.: GPS meteorology: direct estimation of the absolute value of precipitable water, J. Appl. Meteorol., 35, 830-838, 1996. 
Galkin, V. D., Immler, F., Alekseeva, G. A., Berger, F.-H., Leiterer, U., Naebert, T., Nikanorova, I. N., Novikov, V. V., Pakhomov, V. P., and Sal'nikov, I. B.: Analysis of the application of the optical method to the measurements of the water vapor content in the atmosphere - Part 1: Basic concepts of the measurement technique, Atmos. Meas. Tech., 4, 843-856, doi:10.5194/amt-4-843-2011, 2011.

Halthore, R. N., Eck, T. F., Holben, B. N., and Markham, B. L.: Sun photometric measurements of atmospheric water vapor column abundance in the 940-nm band, J. Geophys. Res., 102, 43434352, 1997.

Holben, B. N., Eck, T. F., Slutsker, I., Tanré, D., Buis, J. P., Setzer, A., Vermote, E., Reagan, J. A., Kaufman, Y. J., Nakajima, T., Lavenu, F., Jankowiak, I., and Smirnov, A.: AERONET - a federated instrument network and data archive for aerosol characterization, Remote Sens. Environ., 66, 1-16, 1998.

Holben, B. N., Tanre, D., Smirnov, A., Eck, T. F., Slutsker, I., Abuhassan, N., Newcomb, W. W., Schafer, J. S., Chatenet, B., Lavenu, F., Kaufman, Y. J., Vande Castle, J., Setzer, A., Markham, B., Clark, D., Frouin, R., Halthore, R., Karneli, A., O'Neill, N. T., Pietras, C., Pinker, R. T., Voss, K., and Zibordi, G.: An emerging ground-based aerosol climatology: aerosol optical depth from AERONET, J. Geophys. Res., 106, 12067-12097, 2001.

Kaufman, Y. J. and Gao, B. C.: Remote sensing of water vapor in the near IR from EOS/MODIS, IEEE T. Geosci. Remote, 30, 871884, 1992.

Kieffer, H. H. and Stone, T. C.: The spectral irradiance of the moon, Astron. J., 129, 2887-2901, 2005.

Kouba, J.: A Guide to Using International GNSS Service (IGS) Products, May 2009.

Miloshevich, L. M., Vömel, H., Whiteman, D. N., and Leblanc, T.: Accuracy assessment and correction of Vaisala RS92 radiosonde water vapor measurements, J. Geophys. Res.-Atmos., 114, D11305, doi:10.1029/2008JD011565, 2009.

Ortiz de Galisteo, J. P., Cachorro, V. E., Toledano, C., Rodríguez, E., Berjón, A., and de Frutos, A. M.: Error source in AOD retrieval from filter radiometer data in the UV due to filter band function, Aerosol Sci., 40, 597-602, 2009.

Pougatchev, N., August, T., Calbet, X., Hultberg, T., Oduleye, O., Schlüssel, P., Stiller, B., Germain, K. St., and Bingham, G.: IASI temperature and water vapor retrievals - error assessment and validation, Atmos. Chem. Phys., 9, 6453-6458, doi:10.5194/acp9-6453-2009, 2009.

Romero, P. M., Cuevas, E., Ramos, R., Valdés, M., and Schneider, M.: Programa de vapor de agua en columna del Centro de Investigación Atmosférica de Izaña: análisis e intercomparación de diferentes técnicas de medida, NIPO: 784-09-009-9, Agencia Estatal de Meteorología, Ministerio de Medio Ambiente, y Medio Rural y Marino, Madrid, Spain, 2009.
Romero, P. M., Marrero de la Santa Cruz, C. L., Alonso, S., Cuevas, E., Afonso, S., and Ortiz de Galisteo, J. P.: Una climatología de agua precipitable en la región subtropical sobre la isla de Tenerife basada en datos de radiosondeo, NIPO: 281-12-0075, Agencia Estatal de Meteorología, Ministerio de Medio Ambiente, y Medio Rural y Marino, Madrid, Spain, 2011.

Rothacher, M.: Orbits of Satellite Systems in Space Geodesy, Geodätisch-geophysikalische Arbeiten in der Schweiz, Band 46, Schweizerische Geodätische Kommission, Institut für Geodäsie und Photogrammetrie, Eidg. Technische Hochschule Zurich, Zurich, 1992.

Rothacher, M., Beutler, G., Gurtner, W., Brockmann, E., and Mervart, L.: The Bernese GPS Software Version 3.4, Druckerei der Universität Bern, Astronomical Institute, University of Berne, 1993.

Schmid, B., Thome, K. J., Demoulin, P., Peter, R., Mätzler, C., and Sekler, J.: Comparison of modeled and empirical approaches for retrieving columnar water vapor from solar transmittance measurements in the 0.94- $\mu \mathrm{m}$ region, J. Geophys. Res., 101, 93459358, 1996.

Schmid, B., Michalsky, J. J., Slater, D. W., Barnard, J. C., Halthore, R. N., Liljegren, J. C., Holben, B. N., Eck, T. F., Livingston, J. M., Philip, Russell, B., Ingold, T., and Slutsker, I.: Comparison of columnar water-vapor measurements from solar transmittance methods, Appl. Optics, 40, 1886-1896, 2001.

Schneider, M., Romero, P. M., Hase, F., Blumenstock, T., Cuevas, E., and Ramos, R.: Continuous quality assessment of atmospheric water vapour measurement techniques: FTIR, Cimel, MFRSR, GPS, and Vaisala RS92, Atmos. Meas. Tech., 3, 323338, doi:10.5194/amt-3-323-2010, 2010.

Smirnov, A., Holben, B. N., Eck, T. F., Dubovick, O., and Slutsker, I.: Cloud screening and quality control algorithms for the AERONET database, Remote Sens. Environ., 73, 337-349, 2000.

Trenberth, K. E., Fasullo, J., and Smith, L.: Trends and variability in column-integrated atmospheric water vapour, Clim. Dynam., 24, 741-758, 2005.

Wagner, T., Beirle, S., Grzegorski, M., and Platt, U.: Global trends (1996-2003) of total column precipitable water observed by Global Ozone Monitoring Experiment (GOME) on ERS-2 and their relation to near-surface temperature, J. Geophys. Res., 111, D12102, doi:10.1029/2005JD006523, 2006. 